\title{
Caracterização dos planos de manejo florestal no estado do Piauí
}

\author{
Characterization of forest management plans in the state of Piauí \\ Fabricio Napoleão Andrade ${ }^{\text {I }}$ João Batista Lopes ${ }^{\text {II }}$, Roseli Farias Melo de Barros ${ }^{\text {III }}$, \\ Clarissa Gomes Reis Lopes ${ }^{\mathrm{IV}}$
}

\begin{abstract}
Resumo
A lenha é um dos mais importantes produtos florestais da região Nordeste do Brasil, e cada vez mais é necessário que sua exploração seja feita de maneira sustentável. Nesse sentido, o manejo florestal tem sido uma proposta de significativa melhoria das características ambientais dessa atividade. Este trabalho teve como objetivo identificar e analisar a atividade de exploração florestal por meio de Planos de Manejo Florestal Sustentável (PMFS) no estado do Piauí. Foram analisados dados de localização e produção, no período de 2010-2015. O diagnóstico dos PMFS do Piauí foi realizado por meio de consulta ao banco de dados da coordenação de licenciamento da Secretaria Estadual de Meio Ambiente e Recursos Hídricos - SEMAR, no período de janeiro a março de 2016. Os 96 PMFS detentores de autorização representaram 117.510,60 hectares de área manejada, em propriedades cujas extensões variaram de 67,60 a 34.208,00 ha, com área manejada por propriedade entre 40,00 e 24.969,00 ha. Os talhões adotados para a exploração anual tiveram dimensões entre 7,50 e 1.945,70 ha. O volume anual autorizado, no período, foi de 1.998.986,20 st/ano. A análise dos planos indica que o estado do Piauí possui capacidade de abastecimento de matriz energética proveniente de material lenhoso oriundo do manejo florestal, e que esta atividade, ainda, resulta em significativo benefício ambiental, pelo potencial de sustentabilidade que apresenta.

Palavras-chave: Lenha; Sustentabilidade; Recursos florestais
\end{abstract}

\begin{abstract}
Wood is one of the most important forest products in the northeast of Brazil, and it is increasingly necessary that its exploitation can be carried out in a sustainable way. In this sense, the forest management has been proposing significant improvement of the environmental characteristics of this activity. The objective of this paper was to identify and analyze the activity of forest exploitation through Sustainable Forest Management Plans (PMFS), in the state of Piauí. The localization and the production data analyzed were in the period from 2010 to 2015 . The diagnosis of PMFS in Piauí state was carried out by consulting the database of the licensing coordination of the State Department of Environment and Water Resources (SEMAR), from January to March 2016. The 96 PMFS holders of authorization accounted for more than 117.510,60 hectares of managed area, in properties in which extensions ranged from 67.60 to $34,208.00$ ha, with an area managed by property between 40.00 and 24,969.00 ha. The plots adopted for the annual exploration had dimensions between 7.50 and 1,945.70 ha. The authorized annual volume in the period was $1,998.986 .20 \mathrm{st} /$ year. The analysis of the plans indicates that the state of Piauí has capacity to supply energy matrix from woody material of forest management activities and that this still results in a significant environmental benefit, due to the sustainability potential of the activity.
\end{abstract}

Keywords: Firewood; Sustainability; Forestry resources

\footnotetext{
I Engenheiro Agrônomo, Dr., Universidade Federal do Piauí, Campus Universitário Ministro Petrônio Portella, Bairro Ininga, CEP 64049-550, Teresina (PI), Brasil. fabricionapoleao@yahoo.com.br(ORCID:0000-0002-8365-037X)

II Engenheiro Agrônomo, Dr., Professor do Departamento de Zootecnia, Centro de Ciências Agrárias, Universidade Federal do Piauí, Campus Universitário Ministro Petrônio Portella, Bairro Ininga, CEP 64049-550, Teresina (PI), Brasil. lopesjb@ufpi.edu.br(ORCID: 0000-0002-01334366)

III Bióloga, Dra ., Professora do Departamento de Biologia, Centro de Ciências da Natureza, Universidade Federal do Piauí, Campus Universitário Ministro Petrônio Portella, Bairro Ininga, CEP 64049-550, Teresina(PI), Brasil. rbarros.ufpi@gmail.com(ORCID: 0000-0001-9767-5546)

${ }^{\text {IV }}$ Bióloga, Dra ., Professora do Curso Ciências da Natureza, Centro de Ciências da Natureza, Universidade Federal do Piauí, Campus UniversitárioMinistro Petrônio Portella, Bairro Ininga, CEP 64049-550, Teresina(PI), Brasil. claris-lopes@hotmail.com(ORCID: 0000-00017290-4576)
} 


\section{Introdução}

A grande diversidade vegetal brasileira é largamente utilizada para os mais variados fins, dentre os quais se destaca o madeireiro. Esse tipo de exploração, apesar de alguns avanços tecnológicos, ainda ocorre muitas vezes aquém das legislações e da sustentabilidade. Em termos de nordeste brasileiro, Sampaio (2010) relata que os recursos florestais são de extrema importância para a economia regional, seja na geração de energia, a partir da biomassa na forma de lenha, configurando-se na segunda fonte energética da região, seja na comercialização de produtos florestais madeireiros e não madeireiros por famílias e comunidades, bem como no fornecimento de forragem ao gado criado extensivamente em todo o domínio fitogeográfico da Caatinga.

A Caatinga, com sua enorme extensão, pluralidade de solos, diversidade de condições de disponibilidade de água, ambientes muito distintos e uma gama de restrições ao crescimento, tem diversidade florística alta e com quantidade significativa de espécies adaptadas a períodos de seca (GARIGLIO et al., 2010). Dentre os múltiplos usos da vegetação deste domínio fitogeográfico, as que mais se destacam são: construção civil, medicamentos e combustível (RAMOS et al., 2008; SANTOS; ARAÚJO; ALBUQUERQUE, 2008), sendo a lenha utilizada em casas, comércios e indústrias como fonte energética (PAREYN, 2010). Essa utilização ficou mais acentuada depois que a lenha deixou de ser resultante de outras atividades (agricultura) e passou a ser obtida de maneira direta e independente (SAMPAIO, 2010), por meio da extração legalizada e da atividade de manejo florestal.

Os recursos florestais da Caatinga são perenemente explorados como fonte de matériaprima, e apesar de suas características renováveis, apresentam-se como um desafio para governos, instituições e sociedade, a fim de que a sua utilização ocorra sustentavelmente. Outros desafios, é que sejam levados em consideração na adequação de sua exploração, os aspectos locais ou regionais e as políticas públicas direcionadas ao uso dos recursos florestais desse domínio fitogeográfico (NASCIMENTO; LARH; CARVALHO, 2007).

Dessa forma, a fim de amenizar o passivo ambiental provocado pelo desmatamento nos biomas, incluindo o domínio fitogeográfico Caatinga, criou-se uma alternativa de exploração florestal por meio do manejo florestal. Trata-se de um conjunto de atividades e intervenções planejadas, adaptadas às condições das florestas e aos objetivos sociais e econômicos do seu aproveitamento, que possibilita o seu uso em regime de rendimento sustentável, mantendo sua capacidade produtiva e a diversidade biológica, conduzindo, por sua vez, ao povoamento florestal, com aproveitamento máximo dos recursos básicos disponíveis no solo (LIMA, 2008). Contudo, a prática do manejo florestal sustentável deve obedecer a uma série de regras estabelecidas em dispositivos legais.

No Brasil, a relevância sobre o manejo florestal sustentável aparece pela primeira vez na Lei Federal $n^{0}$ 4.771, de 15 de setembro de 1965, em seu artigo 15, que dizia "fica proibida a exploração sob forma empírica das florestas primitivas da bacia Amazônica que só poderão ser utilizadas em observância a planos técnicos de condução e manejo a serem estabelecidos por ato do Poder Público" (BRASIL, 1965).

No entanto, o termo Manejo Florestal Sustentável (MFS) ganha destaque só em 1992, a partir da Conferência das Nações Unidas sobre Meio Ambiente e Desenvolvimento, no Rio de Janeiro, quando ocorreu ampliação do significado de sustentabilidade florestal.

O Ministério do Meio Ambiente (MMA), fundamentado na Instrução Normativa (IN) $n^{\circ}$ 3, de 04 de maio 2001, reconheceu quatro modalidades de Manejo Florestal (MF): 1) manejo florestal sustentável para fins madeireiros; 2) manejo florestal sustentável de uso múltiplo, 3) manejo florestal sustentável simplificado e 4) manejo florestal sustentável comunitário. A IN supracitada dispõe sobre os termos de referência para elaboração e aprovação dos Planos de Manejo Florestal Sustentável (PMFS) junto ao Instituto Brasileiro do Meio Ambiente e dos Recursos Naturais Renováveis (IBAMA), para atender ao uso de recursos florestais renováveis por associações e comunidades tradicionais da região Nordeste, as quais necessitam da coleta

Ci. Fl., Santa Maria, v. 29, n. 1, p. 243-254, jan./mar., 2019 
de lenha, estacas, toras, frutos, flores, cipós, cascas, para sobrevivência e geração de renda (BRASIL, 2001).

Posteriormente, o MMA criou um regulamento específico, por meio da $\operatorname{IN~}^{\circ} 1$, de 25 de junho de 2009, que dispõe sobre procedimentos técnicos para elaboração, apresentação, execução e avaliação técnica de PMFS da Caatinga e suas formações sucessoras, e dá outras providências. A partir de 2010, a atividade de exploração florestal passou a ser competência dos órgãos estaduais do meio ambiente e o estado do Piauí, por meio da SEMAR e do Conselho Estadual de Meio Ambiente (CONSEMA), criou a Resolução $\mathrm{n}^{\circ}$ 13, de 07 outubro de 2010, que dispõe sobre todas as diretrizes de elaboração e execução dos PMFS, reforçados pela INs $n^{\text {os }} 001$, 002, 003 de 2010, nas quais constam os procedimentos para análise, aprovação e monitoramento dos PMFS no estado do Piauí.

Em 2012, foi aprovado o novo Código Florestal Brasileiro, segundo a Lei Federal $\mathrm{n}^{\mathrm{o}}$ 12.651/2012, que estabelece normas gerais sobre a proteção da vegetação, áreas de preservação permanente e as áreas de reserva legal; a exploração florestal, o suprimento de matéria-prima florestal, o controle da origem dos produtos florestais e o controle e prevenção dos incêndios florestais, e prevê instrumentos econômicos e financeiros para o alcance de seus objetivos. Essa lei abrange o manejo florestal sustentável, comunitário e familiar, incluindo a extração de produtos florestais não madeireiros, desde que não descaracterize a cobertura vegetal nativa existente nem prejudique a função ambiental da área (BRASIL, 2012).

Gariglio (2015) estima que as áreas de Proteção Permanente, de Manejo Florestal e de Reserva Legal em projetos de assentamento contribuem para a conservação de 93.000 ha de Caatinga, com produção bruta de 135.000 st/ano, com renda estimada em 140.000 milhões de reais anuais. Embora existam estudos que acreditam que o manejo florestal da caatinga apresente baixa rentabilidade, provavelmente isso ocorreu pelo baixo estado de conservação em que se encontrava a área estudada (FRANCELINO et al., 2003). Além disso, há estudos que indicam que as árvores da caatinga apresentam elevada qualidade da madeira e potencial energético, pois o poder calorífico e de massa específica são altos, e o teor de cinza é baixo (BRANDT, 2017).

Entretanto, a exploração florestal torna-se preocupante no que diz respeito à questão ambiental, devido ao atendimento da demanda para produção energética ocorrer, principalmente, de forma ilegal (NDAGIJIMANA; PAREYN; RIEGELHAUPT, 2015). E, existe elevada carência de informações relacionadas à atividade de manejo florestal realizada na Caatinga, havendo, portanto, a necessidade de pesquisas, as quais avaliem, caracterizem e quantifiquem o manejo florestal. Diante do exposto, o objetivo principal deste trabalho foi identificar e analisar a atividade de exploração florestal nos PMFS no estado do Piauí, observando variáveis como: localização, quantidade de PMFS, área e produção (volume), por meio da consulta à base de dados do órgão ambiental responsável - SEMAR.

\section{Material e Método}

O estado do Piauí está localizado na região Nordeste do Brasil entre $2^{\circ} 44^{\prime} 22^{\prime \prime}$ e $8^{\circ} 55^{\prime} 37^{\prime \prime}$ de

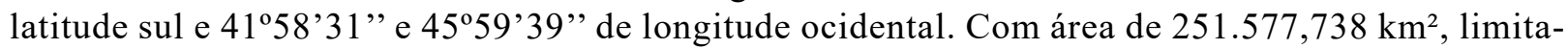
se com Oceano Atlântico (norte); Maranhão (oeste), Ceará e Pernambuco (leste); Bahia e Tocantins (sul) (FUNDAÇÃO CENTRO REGIONAL DE PRODUTIVIDADE DO PIAUÍ, 2013). Assim, de acordo com Farias e Castro (2004), seu território está inserido entre a Pré-Amazônia úmida e o nordeste semiárido, constituindo-se em uma zona de transição climática, com características desses dois domínios geoambientais, sendo que as formações florestais que mais se destacam no Estado, conforme Castro (2000), são: Caatinga com 37\%, ocorrendo no leste e sudoeste do Estado, caracterizada por apresentar porte arbóreo, arbustivo-arbóreo ou arbustivo, com densidades variadas, o Cerrado, com 33\%, e as áreas de transição que correspondem a 19\% do seu território (Figura 1). 
Figura 1 - Mapa dos principais domínios fitogeográficos do estado do Piauí.

Figure 1 - Map of the main phytogeographic domains of the state of Piauí.

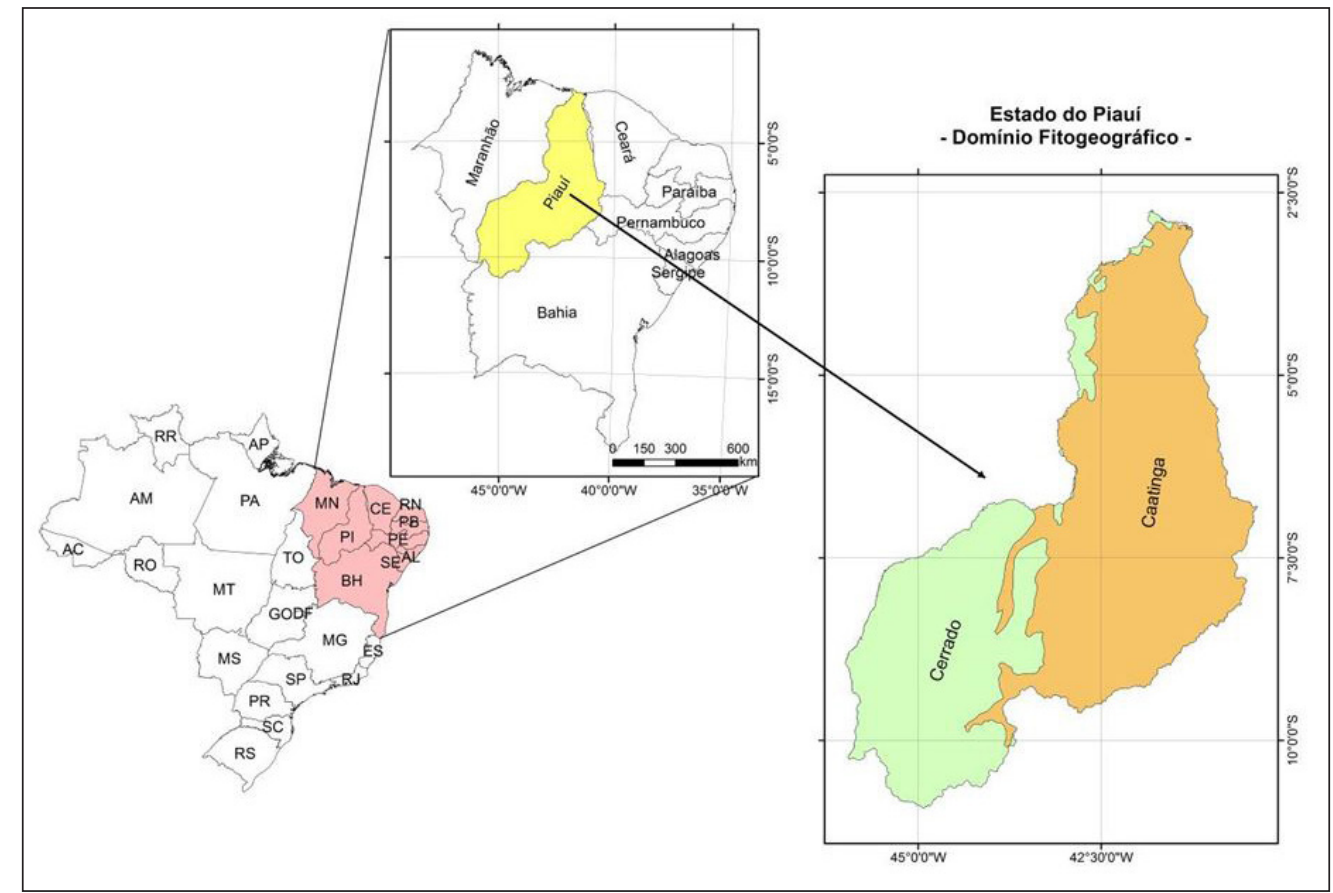

Fonte: IBGE 2004, adaptado pelo autor

O Estado apresenta precipitação pluviométrica anual irregular e diferenciada para cada região, variando entre o total de 400 e $2.000 \mathrm{~mm}$ (ANDRADE JÚNIOR et al., 2004). Utilizouse a análise quantitativa, por ser objetiva e estruturada, cuja fundamentação empírica oportuniza o estabelecimento de verdades universais. Sob esse prisma, Hayati, Karami e Slee (2006) asseguram que os resultados da investigação são reprodutíveis e generalizáveis.

Portanto, este trabalho tem uma abordagem descritiva/explicativa, que para Gil (2000), apresenta como objetivo principal a descrição, interpretação e avaliação das características de determinada população, evento ou fenômeno, como também o encadeamento de correlações entre variáveis.

Considerou-se também, para efeito de identificação e análise das informações, o método documental, que conforme Sá-Silva, Almeida e Guindani (2009, p. 13), "apresenta-se como um método de escolha e de verificação de dados; visa o acesso às fontes pertinentes, e, a esse título, faz parte integrante da heurística de investigação". Assim, o presente estudo foi desenvolvido por meio de coleta do banco de dados junto à Coordenação de Licenciamento e Fiscalização (CLF) do órgão estadual de meio ambiente - SEMAR, realizada no período de janeiro a março de 2016. Foram utilizados e analisados dados correspondentes aos planos de manejo florestais cadastrados a partir de abril de 2010 até dezembro de 2015, sendo esse intervalo de tempo determinado por representar o período em que o órgão estadual passou a ser exclusivamente responsável por todas as atividades florestais a serem licenciadas no Piauí.

Dos planos de manejo florestal madeireiro foram abstraídas informações por mesorregião e município, contemplando a quantificação dos parâmetros: a) número de propriedades com PMFS; b) área total da propriedade, c) área efetiva de manejo, d) área de reserva legal e) volume médio por hectare, f) volume anual autorizado, g) tamanho médio dos talhões. Os dados foram tabulados em planilha do programa Excel, e em sequência analisados por meio de estatísticas descritivas (média, desvio padrão, valores mínimos e máximos) por mesorregião em função dos municípios, de acordo com o Proc Means do Statistical Analysis System (SAS), versão University. 


\section{Resultados e Discussão}

O estado do Piaú apresenta o total de 141 planos de manejos cadastrados, em que quatro estão cancelados, 21 suspensos e 17 em análise, estando 99 autorizados. Do total autorizado, conforme a Figura 2, três planos pertencem ao município de Matias Olímpio, cujo manejo florestal corresponde à exploração de folhas da espécie Pilocarpus sp. (jaborandi), visando à produção de pilocarpina, portanto, não madeireiro e 96 são de atividades de manejo do tipo madeireiro, sendo todos eles com aptidão voltada para a extração de lenha, a ser utilizada como matriz energética. Dos 96 PMFS madeireiro, 14 são do tipo manejo florestal comunitário, desenvolvidos em assentamentos rurais, e $82 \mathrm{em}$ propriedades particulares.

\section{Figura 2 - Município piauiense com atividade de plano de manejo florestal.}

Figure 2 - Piauí municipality with activity of forest management plant.

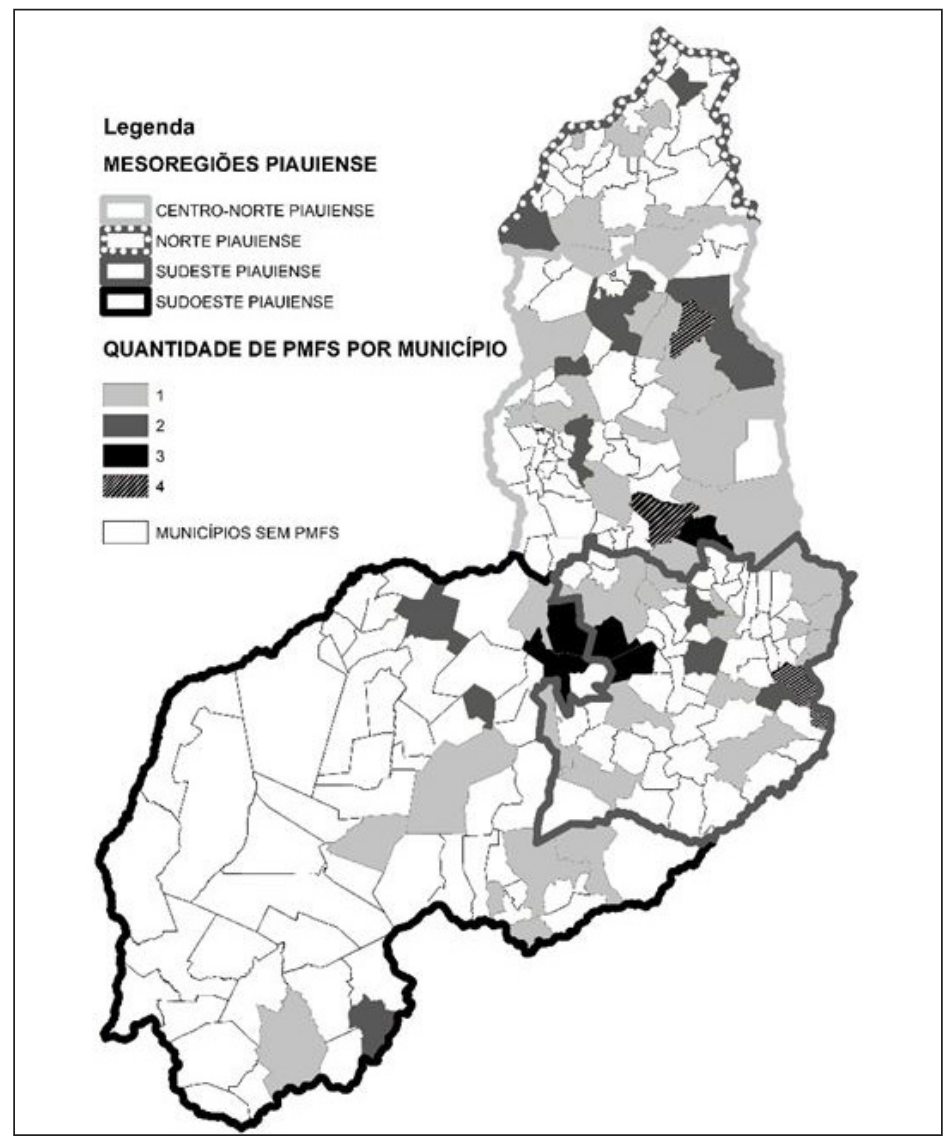

Na Tabela 1, encontram-se os resultados dos parâmetros avaliados dos PMFS madeireiro autorizados, distribuídos por mesorregião e município do estado do Piauí. Os PMFS estão presentes em 66 municípios, abrangendo área total de 188.058,47 hectares, envolvendo o domínio fitogeográfico Caatinga e áreas de transição Cerrado/Caatinga, com valores mínimo e máximo por município, respectivamente, de 67,60 e 34.298,00 hectares, caracterizando grande variação na dimensão das áreas das propriedades. Os recursos florestais nessas propriedades são manejados com as seguintes finalidades: lenha, estacas, mourões, madeira para serraria e carvão. 
Tabela 1 - Dados quantitativos dos planos de manejo florestal sustentável madeireiros aprovados no estado do Piauí em ordem decrescente do tamanho da área total da propriedade.

Table 1 - Quantitative data of the sustainable forest management plans approved in the state of Piauí in decreasing order of the size of the total area of the property.

\begin{tabular}{|c|c|c|c|c|c|c|c|c|}
\hline \multirow{2}{*}{ Mesorregião } & \multirow{2}{*}{ Município } & \multirow{2}{*}{ NP } & \multirow{2}{*}{$\begin{array}{l}\text { ATP } \\
\text { (ha) } \\
\end{array}$} & \multirow{2}{*}{$\begin{array}{c}\text { AEM } \\
\text { (ha) } \\
\end{array}$} & \multirow{2}{*}{$\begin{array}{l}\text { ARL } \\
\text { (ha) }\end{array}$} & \multirow{2}{*}{$\begin{array}{l}\text { VM/ha } \\
\text { (st/ha) }\end{array}$} & \multirow{2}{*}{$\frac{\text { VAA }}{(\text { st/ano })^{*}}$} & \multirow{2}{*}{$\begin{array}{l}\text { TMT } \\
\text { (ha) }\end{array}$} \\
\hline & & & & & & & & \\
\hline \multirow{9}{*}{ Norte } & Bom Princípio & 2 & $5.668,65$ & $1.026,92$ & $1.257,69$ & 98,86 & $4.269,00$ & 16,8 \\
\hline & Caxingó & 1 & $1.581,50$ & 600 & 350 & 139,16 & $7.418,00$ & 40 \\
\hline & Miguel Alves & 2 & $1.400,39$ & 246,62 & 281,05 & 202,32 & $3.010,00$ & 7,5 \\
\hline & Cabeceiras do Piauí & 1 & 565,5 & 335,2 & 121,8 & 216,4 & $3.920,00$ & 25,8 \\
\hline & Brasileira & 1 & 530,8 & 133,68 & 107,37 & 226,55 & $2.948,00$ & 8,91 \\
\hline & Joca Marques & 1 & 286,54 & 229,23 & 57,31 & 213,5 & $3.262,79$ & 15 \\
\hline & Barras & 1 & 183 & 141 & 40,6 & 138 & $1.945,80$ & 14 \\
\hline & Piripiri & 1 & 181,5 & 40 & 36,3 & 248,8 & $4.053,00$ & 40 \\
\hline & Joaquim Pires & 1 & 67,6 & 47,22 & 13,52 & 149,64 & $3.533,00$ & $\mathrm{NI}$ \\
\hline \multirow{20}{*}{ Centro-Norte } & Valença & 4 & $6.122,40$ & $4.628,00$ & $1.219,65$ & 288,61 & $115.157,40$ & 84,06 \\
\hline & Lagoa do Sítio & 3 & $5.085,31$ & $1.104,79$ & $1.041,53$ & 232,26 & $23.940,00$ & 33,27 \\
\hline & $\begin{array}{l}\text { São Miguel do } \\
\text { Tapuio }\end{array}$ & 1 & $3.351,90$ & $2.339,60$ & 670,4 & 404,1 & $72.242,00$ & 204,3 \\
\hline & Juazeiro do Piauí & 4 & $2.745,40$ & $1.487,13$ & 549,25 & 155,82 & $16.498,71$ & 24,6 \\
\hline & Cocal de Telha & 2 & $2.200,57$ & 806 & 490,21 & 165,73 & $13.924,99$ & 39,8 \\
\hline & Campo Maior & 2 & $1.945,16$ & $1.194,00$ & 389,56 & 219,55 & $30.305,00$ & 59,5 \\
\hline & Buriti dos Montes & 2 & $1.701,60$ & 702,1 & 336,05 & 154,5 & $9.232,00$ & 33,69 \\
\hline & Teresina & 1 & $1.616,49$ & 301,54 & 324 & 81,11 & $2.922,53$ & 30,15 \\
\hline & Pimenteiras & 1 & $1.245,70$ & 842,24 & 373,72 & 208,4 & $16.615,73$ & 80 \\
\hline & Curralinhos & 1 & $1.185,06$ & 292,19 & 237,02 & 144,29 & $17.048,50$ & 39 \\
\hline & Beneditinos & 1 & $1.084,72$ & 700 & 217,11 & 166 & $8.050,00$ & 70 \\
\hline & Pau D’arco do Piauí & 2 & 900 & 540 & 180 & 123,17 & $6.826,00$ & 27 \\
\hline & Altos & 1 & 900 & 299,48 & 180 & 168,75 & $3.036,00$ & 20 \\
\hline & Passagem Franca & 2 & 885,45 & 696,43 & 180,32 & 177,35 & $16.286,35$ & 20 \\
\hline & Milton Brandão & 2 & 837,4 & 439,6 & 167,5 & 223,5 & $6.808,00$ & 17 \\
\hline & Sigefredo Pacheco & 1 & 740 & 400 & 148 & 298,12 & $11.924,80$ & 40 \\
\hline & Castelo do Piauí & 1 & 642,02 & 113 & 128,4 & 131 & $1.446,45$ & 11 \\
\hline & Monsenhor Gil & 1 & 423,6 & 247,88 & 84,72 & 292 & $17.520,00$ & 36,5 \\
\hline & Elesbão Veloso & 1 & 353,5 & 269,27 & 72,2 & 161,11 & $3.947,20$ & 24,5 \\
\hline & Inhuma & 1 & 337,2 & 269 & 68,2 & 92,73 & $2.636,92$ & 22,5 \\
\hline \multirow{4}{*}{ Sudeste } & Simões & 4 & $9.549,92$ & $6.687,10$ & $1.914,64$ & 207,25 & $90.677,93$ & 114,86 \\
\hline & Colônia do Piauí & 3 & $7.679,09$ & $5.821,60$ & $1.541,17$ & 394,06 & $165.346,02$ & 146,67 \\
\hline & Pio IX & 1 & $5.842,59$ & $5.382,19$ & $2.540,57$ & 100,95 & $38.800,00$ & 194,13 \\
\hline & $\begin{array}{l}\text { Santo Inácio do } \\
\text { Piauí }\end{array}$ & 3 & $4.881,48$ & $3.408,14$ & 994,23 & 283,5 & $80.973,51$ & 84,33 \\
\hline
\end{tabular}


Tabela 1 - Conclusão...

Table 1 - Conclusion...

\begin{tabular}{|c|c|c|c|c|c|c|c|c|}
\hline \multirow[t]{2}{*}{ Mesorregião } & \multirow[t]{2}{*}{ Município } & \multirow[t]{2}{*}{$\mathbf{N P}$} & \multirow{2}{*}{$\begin{array}{l}\text { ATP } \\
\text { (ha) } \\
\end{array}$} & \multirow{2}{*}{$\begin{array}{c}\text { AEM } \\
\text { (ha) }\end{array}$} & \multirow{2}{*}{$\begin{array}{c}\text { ARL } \\
\text { (ha) }\end{array}$} & \multirow{2}{*}{$\begin{array}{l}\text { VM/ha } \\
\text { (st/ha) }\end{array}$} & \multirow{2}{*}{$\frac{\text { VAA }}{(\text { st/ano })^{*}}$} & \multirow{2}{*}{$\frac{\text { TMT }}{\text { (ha) }}$} \\
\hline & & & & & & & & \\
\hline \multirow{16}{*}{ Sudeste } & Picos & 2 & $1.544,53$ & 508,1 & 309,61 & 196,5 & $6.830,55$ & 33 \\
\hline & Simplício Mendes & 1 & $1.316,36$ & 881,17 & 269,27 & 267,64 & $15.188,83$ & 65 \\
\hline & São João do Piauí & 1 & 990,8 & 500 & 198,1 & 178,5 & $4.835,00$ & 32 \\
\hline & Marcolândia & 1 & 910 & 504,38 & 220 & 226,26 & $5.566,82$ & 30 \\
\hline & Caridade do Piauí & 2 & 642,5 & 458,02 & 137,04 & 146,62 & $6.132,75$ & 18,45 \\
\hline & Ipiranga & 1 & 605,01 & 376,2 & 125,14 & 347 & $10.589,00$ & 40 \\
\hline & Oeiras & 1 & 440 & 254,42 & 88 & 219,31 & $4.466,24$ & 20 \\
\hline & Caldeirão Grande & 1 & 380,95 & 245,77 & 77 & 177,46 & $3.501,29$ & 15 \\
\hline & Sussuapara & 1 & 372,7 & 160,27 & 74,54 & 238,91 & $2.588,00$ & 13 \\
\hline & Itainópolis & 2 & 352,1 & 277,18 & 70,42 & 228,05 & $2.184,00$ & 11,85 \\
\hline & Geminiano & 1 & 329,93 & 249,04 & 66 & 443,02 & $4.112,43$ & 16 \\
\hline & Alegrete & 1 & 235 & 184,14 & 47 & 159,51 & $1.962,03$ & 12 \\
\hline & Fronteiras & 1 & 209,01 & 134,31 & 41,8 & 136,82 & $1.771,00$ & 11 \\
\hline & Paulistana & 1 & 209 & 143,29 & 47,96 & 152,24 & $1.761,41$ & 10 \\
\hline & São João da Varjota & 1 & 199,2 & 104,94 & 39,84 & 271,85 & $2.286,20$ & 9,94 \\
\hline & Jacobina/Patos & 1 & 173,11 & 134,82 & 35 & 481,84 & $3.964,54$ & 9 \\
\hline \multirow{13}{*}{ Sudoeste } & Canto do Buriti & 1 & $34.208,00$ & $24.969,00$ & $5.028,00$ & 244,7 & $152.656,00$ & $1.945,70$ \\
\hline & Parnaguá & 1 & $20.326,02$ & $14.635,65$ & $4.065,20$ & 226,5 & $220.837,50$ & 975 \\
\hline & São José do Peixe & 3 & $18.052,10$ & $8.856,04$ & $3.658,70$ & 268,74 & $161.404,00$ & 198,93 \\
\hline & Avelino Lopes & 2 & $6.733,61$ & $4.720,00$ & $1.346,72$ & 168,52 & $61.360,44$ & 235 \\
\hline & Rio Grande do Piauí & 2 & $5.982,29$ & $4.572,32$ & $1.198,00$ & 534,08 & $195.527,30$ & 171 \\
\hline & $\begin{array}{c}\text { São Francisco do } \\
\text { Piauí }\end{array}$ & 3 & $5.511,82$ & $4.000,73$ & $1.107,83$ & 341 & $122.582,95$ & 102,67 \\
\hline & Cristino Castro & 1 & $5.428,80$ & $3.637,28$ & $1.049,76$ & 251,52 & $86.303,40$ & 82 \\
\hline & $\begin{array}{l}\text { São Raimundo } \\
\text { Nonato }\end{array}$ & 1 & $2.345,16$ & $1.854,40$ & 469,16 & 374,5 & $46.362,00$ & 138,2 \\
\hline & Nazaré do Piauí & 1 & $1.656,59$ & $1.321,07$ & 335,52 & 297,12 & $34.045,17$ & 100 \\
\hline & Jerumenha & 2 & 728,1 & 484,17 & 145,62 & 196,33 & $8.727,00$ & 22,5 \\
\hline & Fartura do Piauí & 1 & 583,24 & 422,74 & 116,7 & 279,55 & $10.611,71$ & 43 \\
\hline & Coronel José Dias & 1 & 505 & 200 & 101 & 150,45 & $2.004,00$ & 13,3 \\
\hline & Anísio de Abreu & 1 & 225 & 150 & 45 & 153,27 & $2.299,00$ & 15 \\
\hline
\end{tabular}

Em que: $\mathrm{NP}=$ Número de propriedades; ATP = Área total das propriedades; $\mathrm{AEM}=$ Área efetiva de manejo; ARL =Área de Reserva Legal;

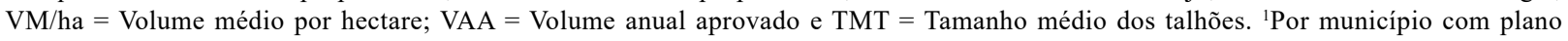
autorizado.

Dos nove municípios da Mesorregião Norte com planos de manejo florestal madeireiro sustentável, Bom Princípio, com dois planos aprovados, apresentou maior área efetiva de manejo e volume recomendado de 4.269 st/ano. Neste sentido, a Mesorregião Centro Norte contou com 20 municípios e 34 planos de manejo aprovados (Tabela 1), dos quais se destacou Valença, com quatro planos de manejo aprovados com área efetiva de manejo de 4.628,00 ha e volume anual de 115.157,40 st. Já, a Mesorregião Sudeste envolveu 22 municípios, contemplando 31 planos de manejo aprovados, em que os munícipios de Colônia do Piauí e Simões se destacaram com o total de sete planos aprovados com volume de 165.346,02 e 90.677,93 st/ano, respectivamente. A Mesorregião Sudoeste, englobando 13 municípios, apresenta a maior área manejada aprovada e também o maior volume anual recomendado com 1.998.986,19 st.

A área efetivamente manejada é de 117.510,60 hectares, apresentando produção volumétrica média por hectare de 222,06 $\pm 94,19$ st/ha de lenha por município com planos autorizados, resultando em 145,73 
st/ha de lenha por plano. Estes dados demonstram aumento tanto no número de planos (12,94\%) quanto na área total manejada $(11,94 \%)$, quando comparados com os dados presentes no Centro Nordestino de Informações sobre Plantas (CNIP), que apresenta o total de 85 planos com área de 104.974,00 ha manejada no Estado até 2012 (CENTRO NORDESTINO DE INFORMAÇÕES SOBRE PLANTAS, 2012). O volume anual aprovado é $1.998 .986,19$ st/ano, em que o menor e o maior valor por município com plano de manejo autorizado foi de $1.446,45$ st/ano e $220.837,50$ st/ano, respectivamente.

Dentre os municípios no estado do Piauí com atividades de MFS destacam-se Simões, Valença do Piauí e Juazeiro do Piauí quanto ao número de propriedades, que apresentam quatro planos cada um, sendo que Simões e Valença do Piauí, também, merecem destaque quanto à área total das propriedades, 9.549,92 ha e 6.122,40 ha, respectivamente. Ainda em relação a este último dado, os municípios de Canto do Buriti e Parnaguá possuem as maiores áreas totais, apresentando em apenas uma propriedade, 34.208,00 ha e 20.306,02 ha, respectivamente. Ressalta-se que o município de São José do Peixe, também, apresenta elevada área total de propriedades com PMFS totalizando 18.058,10 ha (em três planos). Cabe ainda enfatizar, a presença de planos cujas propriedades possuem área inferior a 200 ha, presentes nos municípios de São João da Varjota (199,20 ha), Barras (183,00 ha), Piripiri (181,50 ha), Jacobina/Patos (173,11 ha) e Joaquim Pires (67,60 ha).

Para a área efetiva de manejo, os seis maiores municípios em relação aos valores de áreas totais de propriedades absorvem $66.351,58$ ha, equivalendo a $56,46 \%$ do valor total das áreas manejadas no Estado. Neste parâmetro, o estado do Piauí só apresenta valor inferior ao estado do Ceará (149.391,00 ha), cabendo ressaltar que este total de área manejada está presente em 284 propriedades (CENTRO NORDESTINO DE INFORMAÇÕES SOBRE PLANTAS, 2012).

A quantidade de área destinada à reserva legal em todos os PMFS encontra-se em conformidade com a Lei Federal n $\mathrm{n}^{\mathrm{0}}$ 12.651, de 25 de maio de 2012 (Código Florestal), em que se destina um mínimo de $20 \%$ da área total da propriedade. Infere-se que mesmo com a utilização das áreas com a atividade de manejo florestal, a conservação/preservação contempla mais de 155 mil hectares na Caatinga e transição Cerrado/ Caatinga, equivalente à soma das reservas legais $(37.553,65 \mathrm{ha})$ com as áreas efetivamente manejadas (117.510,60 ha). Se for considerada a baixa efetividade de proteção deste domínio fitogeográfico, que apresenta apenas $7,3 \%$ de sua área protegida (BRASIL, 2011), esses números já podem ser considerados significativos no tocante à conservação/preservação da Caatinga.

Os municípios de Rio Grande do Piauí, Jacobina/Patos, Geminiano e São Miguel do Tapuio foram os que apresentaram maior rendimento de material lenhoso por hectare, evidenciando valores acima de $400 \mathrm{st} / \mathrm{ha}$. Já os municípios de Bom Princípio (98,86 st/ha) Inhuma (92,73 st/ha) e Teresina (81,11 st/ha) apresentaram valores abaixo de $100 \mathrm{st} / \mathrm{ha}$. Esses valores podem ser decorrentes da grande variedade de fisionomias da Caatinga, presentes no estado do Piauí, variando desde uma Caatinga arbórea densa, até áreas com vegetação arbustiva aberta. Campello (2009), trabalhando com diferentes fitofisionomias de Caatinga, encontrou valores produtivos semelhantes com os desta pesquisa para os estados do Rio Grande do Norte e Ceará, variando entre 70 - 170 st/ha e 119 - 215 st/ha, respectivamente, enquanto que Meunier (2014) registrou valor de 150,15 st/ha no estado de Pernambuco.

O volume anual autorizado, em PMFS no estado Piauí para lenha foi de 1.998.986,20 st/ano. Quanto a esses volumes, destacam-se os municípios de Rio Grande do Piauí, Valença, Colônia do Piauí, Parnaguá, São Francisco do Piauí, São José do Peixe e Canto do Buriti, por representarem 56,70\% do volume total de PMFS liberado no Estado. Esses valores apresentam-se similares aos autorizados em anos anteriores no estado de Pernambuco (1.891.798,75 st/ano) (BANCO DO NORDESTE, 2012).

Quanto aos dados referentes às Unidades de Produção Anuais (UPA) explorados no Piauí, os valores oscilam entre de 7,50 ha e 1.945,70 ha, com tamanho médio de 96,72 ha por UPA. Meunier (2014) encontrou tamanhos mínimos e máximos de UPA na Caatinga Pernambucana inferiores aos piauienses, variando de 3,05 ha a 302,75 ha, respectivamente. Esses dados demonstram que o estado do Piauí apresenta áreas efetivamente manejadas maiores visto o tamanho das UPAs, justificadas por estas se encontrarem em localização que permite melhor fluxo de seus produtos pela proximidade com polos gesseiros, projetos de carvoejamento, cerâmicas e empreendimentos alimentícios.

De acordo com a Tabela 2, as mesorregiões Centro-Norte, com 31 planos de manejo, e a Sudeste, com 20, destacam-se quanto ao número de propriedades, representando $77,27 \%$ planos autorizados 
no Estado. Quanto ao volume anual autorizado (VAA), destaca-se a mesorregião sudoeste, com

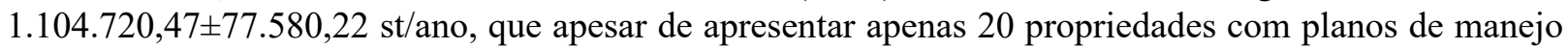
autorizados, supera todas as demais mesorregiões absorvendo 55,26\% do VAA no Estado. Também, foi constatado que o menor e o maior valor do VAA entre os munícipios desta mesorregião foi de 2.004,00 e

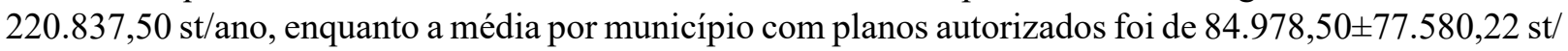
ano, apresentando grande variabilidade. O mesmo aspecto se observa quanto à área total das propriedades (ATP) e no tamanho das áreas efetivamente manejadas (AEM), em que essa mesorregião apresenta, respectivamente, $54,39 \%$ e $59,42 \%$ dos valores analisados.

A mesorregião Norte apresenta os menores valores para todos os dados analisados, com área média total por propriedade entre os municípios de 1.162,83 $\pm 1.774,15$ ha e área média efetivamente manejada por município de $311,10 \pm 318,36$ ha, com volume médio por hectare de 181,47 $\pm 50,95$ st/ano. O número de planos por município oscilou entre um e quatro. Diante destes resultados observados, constata-se o grande potencial energético que o estado do Piauí apresenta, considerando os 96 planos de manejo sustentável, devidamente, autorizados, em que a área total das propriedades representa $188.058,47 \pm 5.496,88$ ha, tendo volume anual aprovado médio por município de 31.729,94 $\pm 52.228,57$ estéreos, com talhões de tamanho médio de 98,28 $\pm 271,27$ ha, bem como área média de reserva legal por município de 597,72 $\pm 52.228,57$ ha, atendendo à legislação vigente. Neste contexto, constata-se que nos diversos parâmetros avaliados existe grande variabilidade, tanto dentro dos planos autorizados nas mesorregiões de forma global como, envolvendo o estado do Piauí como um todo.

Tabela 2 - Valores mínimo, máximo, médio, desvio padrão e total dos parâmetros avaliados por mesorregião e do Piauí.

Table 2 - Minimum, maximum, mean, standard deviation and total values of the parameters evaluated by mesoregion and Piauí.

\begin{tabular}{|c|c|c|c|c|c|c|c|c|}
\hline \multirow{2}{*}{ Mesorregião } & \multirow{2}{*}{ Município } & \multirow{2}{*}{ NP } & \multirow{2}{*}{$\begin{array}{l}\text { ATP } \\
\text { (ha) }\end{array}$} & \multirow{2}{*}{$\begin{array}{l}\text { AEM } \\
\text { (ha) }\end{array}$} & \multirow{2}{*}{$\begin{array}{l}\text { ARL } \\
\text { (ha) }\end{array}$} & \multirow{2}{*}{$\begin{array}{l}\text { VM/ha } \\
\text { (st/ha) }\end{array}$} & \multirow{2}{*}{$\begin{array}{l}\text { VAA } \\
\text { (st/ano)* }\end{array}$} & \multirow{2}{*}{$\begin{array}{l}\text { TMT } \\
\text { (ha) }\end{array}$} \\
\hline & & & & & & & & \\
\hline \multirow{5}{*}{ Norte } & Mínimo & 1 & 67,6 & 40 & 13,52 & 98,86 & 1945,8 & 7,5 \\
\hline & Máximo & 2 & 5668,65 & 1026,92 & 1257,69 & 248,8 & 7418 & 40 \\
\hline & Média1 & 1,2 & 1162,83 & 311,1 & 251,74 & 181,47 & 3817,73 & 21 \\
\hline & $\begin{array}{c}\text { Desvio } \\
\text { Padrão1 }\end{array}$ & 0,4 & 1774,15 & 318,36 & 394,61 & 50,95 & 1522,06 & 12,96 \\
\hline & Total & 11 & $10.465,48$ & $2.799,87$ & $2.265,64$ & 1633,2 & $34.359,59$ & 168 \\
\hline \multirow{5}{*}{ Centro-Norte } & Mínimo & 1 & 353,5 & 113 & 72,2 & 81,11 & 1446,45 & 11 \\
\hline & Máximo & 4 & $6.122,40$ & $4.628,00$ & $1.219,65$ & 404,1 & $115.157,40$ & 204,3 \\
\hline & Médial & 1,7 & 1715,17 & 883,61 & 352,89 & 194,41 & 19818,43 & 45,84 \\
\hline & $\begin{array}{c}\text { Desvio } \\
\text { Padrão1 }\end{array}$ & 1 & 1556,49 & 1028,32 & 313,43 & 78,73 & 27288,76 & 42,58 \\
\hline & Total & 34 & $34.303,48$ & $17.672,25$ & $7.057,84$ & $3.888,10$ & $396.368,58$ & 916,87 \\
\hline \multirow{5}{*}{ Sudeste } & Mínimo & 1 & 173,11 & 104,94 & 35 & 100,95 & 1761,41 & 9 \\
\hline & Máximo & 4 & 9549,92 & 6687,1 & 2540,57 & 481,84 & 165346,02 & 194,13 \\
\hline & Média1 & 1,5 & 1952,56 & 1295,96 & 460,26 & 237,25 & 22073,22 & 46,01 \\
\hline & $\begin{array}{c}\text { Desv. } \\
\text { Padrão1 }\end{array}$ & 0,9 & 2764,46 & 2083,79 & 708,85 & 103,9 & 41270,61 & 51,17 \\
\hline & Total & 31 & $41.003,78$ & $27.215,08$ & $9.665,43$ & 4982,29 & $463.537,55$ & 966,23 \\
\hline
\end{tabular}


Tabela 2 - Conclusão...

Table 2 - Conclusion...

\begin{tabular}{|c|c|c|c|c|c|c|c|c|}
\hline \multirow{2}{*}{ Mesorregião } & \multirow{2}{*}{ Município } & \multirow{2}{*}{ NP } & \multirow{2}{*}{$\begin{array}{l}\text { ATP } \\
\text { (ha) }\end{array}$} & \multirow{2}{*}{$\begin{array}{l}\text { AEM } \\
\text { (ha) }\end{array}$} & \multirow{2}{*}{$\begin{array}{l}\text { ARL } \\
\text { (ha) }\end{array}$} & \multirow{2}{*}{$\begin{array}{l}\text { VM/ha } \\
\text { (st/ha) }\end{array}$} & \multirow{2}{*}{$\begin{array}{l}\text { VAA } \\
\text { (st/ano)* }\end{array}$} & \multirow{2}{*}{$\begin{array}{l}\text { TMT } \\
\text { (ha) }\end{array}$} \\
\hline & & & & & & & & \\
\hline \multirow{5}{*}{ Sudoeste } & Mínimo & 1 & 225 & 150 & 45 & 150,45 & $2.004,00$ & 13,3 \\
\hline & Máximo & 3 & $34.208,00$ & $24.969,00$ & $5.028,00$ & 534,08 & $220.837,50$ & 1945,7 \\
\hline & Média1 & 1,5 & $7.868,13$ & $5.371,03$ & $1.435,94$ & 268,18 & $84.978,50$ & 310,95 \\
\hline & $\begin{array}{c}\text { Desv. } \\
\text { Padrão1 }\end{array}$ & 0,8 & $10.225,85$ & $7.182,96$ & $1.691,78$ & 105,28 & $77.580,22$ & 551,71 \\
\hline & Total & 20 & $102.285,73$ & $69.823,40$ & $18.667,21$ & $3.486,28$ & $1.104 .720,47$ & $4.042,30$ \\
\hline \multirow{5}{*}{ Piauí } & Mínimo & 1 & 67,6 & 40 & 13,52 & 81,11 & $1.446,45$ & 7,5 \\
\hline & Máximo & 4 & $34.208,00$ & $24.969,00$ & $5.028,00$ & 534,08 & $220.837,50$ & $1.945,70$ \\
\hline & Média Geral1 & 1,5 & $2.985,06$ & 1865,25 & 597,72 & 222,06 & $31.729,94$ & 98,28 \\
\hline & $\begin{array}{c}\text { Desv. } \\
\text { Padrãol }\end{array}$ & 0,8 & $5.496,88$ & 3882,3 & 978,1 & 94,19 & $52.228,57$ & 271,27 \\
\hline & Total Geral & 96 & $188.058,47$ & $117.510,60$ & $37.556,12$ & $13.989,90$ & $1.998 .986,19$ & $6.093,41$ \\
\hline
\end{tabular}

Em que: $\mathrm{NP}=$ Número de propriedades; ATP = Área total das propriedades; AEM = Área efetiva de manejo; ARL =Área de Reserva Legal; VM/ ha $=$ Volume médio por hectare; VAA = Volume anual aprovado e TMT = Tamanho médio dos talhões. ${ }^{1}$ Por município com plano autorizado.

${ }^{1}$ Valores médios dos municípios.

\section{Conclusões}

Diante dos dados observados, constatou-se que o estado do Piauí está abastecido de lenha legalizada de PMFS presentes em 55 municípios, podendo ser destinada a cerâmicas, polos gesseiros, projetos de carvoejamentos, empreendimentos alimentícios dentre outros. Destaca-se o incremento na produção anual, com valores médios acima de valores obtidos em outros planos no Nordeste.

Com a análise dos Planos constantes do banco de dados da SEMAR, observou-se que o estado do Piauí possui capacidade de abastecimento de matriz energética proveniente de material lenhoso de atividades de manejo florestal, sendo que a forma como os planos de manejo são executados contribui para a manutenção da estrutura e composição de espécies no povoamento florestal remanescente após a exploração florestal, que somado à necessidade de apresentação de área de reserva legal e área de preservação permanente (caso exista) para fazer cumprir as exigências legais, podem promover significativo benefício ambiental.

Ressalta-se que novos estudos devem ser realizados para obtenção de informações sobre as principais espécies manejadas, capacidade de rebrota, melhorias nas condições socioeconômicas e ambientais das comunidades, bem como dos municípios onde estes planos de manejo vêm sendo implantados dando ênfase ao mercado consumidor.

\section{Referências}

ANDRADE JÚNIOR, A. S. et al. Classificação climática do estado do Piauí. Teresina: EMBRAPA Meio-Norte, 2004. 86 p. (Documentos, 86).

BANCO DO NORDESTE. Manejo florestal: uma possibilidade de parceria entre calcinadores e apicultores na Chapada do Araripe (PE). Informe Rural Etene, [S.1.], v. 6, n. 3, nov. 2012.

BRANDT, M. A. Potencial de uso da biomassa florestal da caatinga, sob manejo sustentável, para geração de energia. Ciência Florestal, Santa Maria, v. 27, n. 1, p. 117-127, 2017.

BRASIL. Instituto Brasileiro do Meio Ambiente e dos Recursos Naturais Renováveis. Instrução Normativa $n^{0} 03$ de 04 de maio de 2001. Disponível em: http://www.mp.go.gov.br/nat_sucroalcooleiro/ 
Documentos/legislacao/Geral/florestas/flo6.pdf. Acesso em: 25 jun. 2015.

BRASIL. Lei $n^{0}$ 4.771, de 15 de setembro de 1965. Código Florestal. Disponível em: http://www. planalto.gov.br/ccivil_03/leis/14771.htm. Acesso em: 25 jun. 2015.

BRASIL. Lei $\mathbf{n}^{0}$ Lei 12.651 de 25 de maio de 2012. Dispõe sobre a proteção da vegetação nativa; altera as Leis nos 6.938, de 31 de agosto de 1981, 9.393, de 19 de dezembro de 1996, e 11.428, de 22 de dezembro de 2006; revoga as Leis nos 4.771, de 15 de setembro de 1965, e 7.754, de 14 de abril de 1989, e a Medida Provisória no 2.166-67, de 24 de agosto de 2001; e dá outras providências. Disponível em: http://www. planalto.gov.br/ccivil_03/leis/14771.htm. Acesso em: 25 jun. 2015.

BRASIL. Ministério do Meio Ambiente. Quarto relatório nacional para a convenção sobre diversidade biológica: Brasil. Brasília: MMA, 2011. 248 p.

CAMPELLO, F. B. Uso sustentável integrado da biodiversidade na caatinga. [S.1.: s.n.], 2009. Disponível em: http://www.sbs.org.br/destaques_usosustentavel.htm. Acesso em: 26 jun. 2016.

CASTRO, A. A. J. F. Cerrados do Brasil e do Nordeste: produção, hoje, deve também incluir manutenção da biodiversidade. In: BENJAMIN, A. H.; SÍCOLI, J. M. C. (Ed.). Agricultura e meio ambiente. São Paulo: IMESP, 2000. p. 79-87.

CENTRO NORDESTINO DE INFORMAÇÕES SOBRE PLANTAS. APNE - Associação Plantas do Nordeste. [S.1.]: CNIP, 2012. Disponível em: http://www.cnip.org.br/planos_manejo.html. Acesso em: 25 jun. 2016.

FARIAS, R. R. S.; CASTRO, A. A. J. F. Fitossociologia de trechos da vegetação do Complexo de Campo Maior, Campo Maior, PI, Brasil. Acta Botanica Brasílica, Porto Alegre, v. 18, n. 4, p. 949-963, 2004.

FRANCELINO, M. R. et al. Contribuição da caatinga na sustentabilidade de projetos de assentamentos no sertão Norte-rio-grandense. Revista Árvore, Viçosa, MG, v. 27, n. 1, p. 79-86, 2003.

FUNDAÇÃO CENTRO REGIONAL DE PRODUTIVIDADE DO PIAUÍ. Fundação CEPRO: Piauí em números. 10. ed. Teresina: CEPRO, 2013.

GARIGLIO, M. A. Manejo florestal sustentável em assentamentos rurais na caatinga. In: PAREYN, F.; VIEIRA, J. L.; GARIGLIO, M. A. Estatística Florestal da Caatinga. Recife: Associação Plantas do Nordeste, 2015. v. 2. p. 6-17.

GARIGLIO, M. A. et al. Uso sustentável e conservação dos recursos florestais da Caatinga. Brasília: Serviço Florestal Brasileiro, 2010. 368 p.

GIL, A. C. Técnicas de pesquisas em economia e elaboração de monografias. 3. ed. São Paulo: Atlas, 2000 .

HAYATI, D.; KARAMI, E.; SLEE, B. Combining qualitative and quantitative methods in the measurement of rural poverty. Social Indicators Research, Dordrecht, v. 75, p. 361-394, 2006.

IBGE. Mapa de vegetação do Brasil. [S.1.]: IBGE, 2004. Disponível em: http://mapas.ibge.gov.br/ tematicos/vegetacao. Acesso em: 20 mar. 2016.

LIMA, M. F. Curso sobre análise de planos de manejo florestal sustentável no bioma Caatinga. Patos: Ministério do Meio Ambiente; Programa das Nações Unidas para o desenvolvimento, 2008.

MEUNIER, I. M. J. Análises de sustentabilidade de planos de manejo florestal em Pernambuco. 2014. 137 f. Tese (Doutorado) - Universidade Federal Rural de Pernambuco, Departamento de Ciência Florestal, 2014.

NASCIMENTO, M. F.; LAHR, F. A. R.; CARVALHO, A. J. E. Fabricação de chapas de partículas homogêneas com madeiras nativas e exóticas adaptadas do semi-árido do Brasil. Boletim Técnico, [S.1.], n. 6 , jun. 2007.

NDAGIJIMANA, C.; PAREYN, F. G. C.; RIEGELHAUPT, E. Uso do solo e desmatamento da caatinga: 
um estudo de caso na Paraíba e no Ceará - Brasil. In: PAREYN, F.; VIEIRA, J. L.; GARIGLIO, M. A. Estatística Florestal da Caatinga. Recife: Associação Plantas do Nordeste, 2015. v. 2. p. 18-29.

PAREYN, F. G. C. Os recursos florestais nativos e a sua gestão no estado de Pernambuco - o papel do manejo florestal sustentável. In: GARIGLIO, M. A. et al. (Org.). Uso sustentável e conservação dos recursos florestais da caatinga. Brasília: Serviço Florestal Brasileiro, 2010. p. 99-112.

RAMOS, M. A. et al. Use and knowledge of fuelwood in an area of Caatinga vegetation in NE Brazil. Biomass and Bioenergy, Oxford, v. 32, p. 510-517, 2008.

SAMPAIO, E. V. S. B. Características e Potencialidades. Caracterização do Bioma Caatinga. In: GARIGLIO, M. A. et al. (Org.). Uso sustentável e conservação dos recursos florestais da Caatinga. Brasília: Serviço Florestal Brasileiro, 2010.

SANTOS, J. P.; ARAÚJO, E. L.; ALBUQUERQUE, U. P. Richness and distribution of useful woody plants in the semi-arid region of northeastern Brazil. Journal of Arid Environments, London, v. 72, p. 652-663, 2008.

SÁ-SILVA, J. R.; ALMEIDA, C. D.; GUINDANI, J. F. Pesquisa documental: pistas teóricas e metodológicas. Revista Brasileira de História e Ciências Sociais, São Leopoldo, v. 1, n. 1, p. 1-15, jul. 2009. 